\title{
Surgical Treatment for Epiphora: Do not Overlook the Lacrimal Gland
}

\author{
Jorge Schwember ${ }^{1 *}$, Carlos Barría ${ }^{2}$, Luisa Madrid ${ }^{1}$, Luisella Yori ${ }^{3}$ and Fabiola Bustamante ${ }^{4}$ \\ ${ }^{1}$ Centro Laser, La Serena, Chile \\ ${ }^{2}$ Histomed, La Serena, Chile \\ ${ }^{3}$ CESFAM Manuel Rodriguez, Copiapó, Chile \\ ${ }^{4}$ Universidad Mayor, Escuela de Medicina, Santiago, Chile
}

*Corresponding author: Jorge Schwember, Centro Laser, Huanhuali 735, La Serena, 1720412, Chile, E-mail: jschwember@centrolaserlaserena.cl

Received: 18 Dec, 2018 | Accepted: 21 Jan, 2019 | Published: 25 Jan, 2019

Citation: Schwember J, Barría C, Madrid L, Yori L, Bustamante F (2019) Surgical Treatment for Epiphora: Do not Overlook the Lacrimal Gland. J Clin Cosmet Dermatol 3(1): dx.doi.org/10.16966/2576-2826.137

Copyright: ( 2019 Schwember J, et al. This is an open-access article distributed under the terms of the Creative Commons Attribution License, which permits unrestricted use, distribution, and reproduction in any medium, provided the original author and source are credited.

\begin{abstract}
Epiphora is a condition resulting from Hyper-secretion of Tears (HT) from the lacrimal gland, eyelid malposition, obstruction or absence of lacrimal ducts and treatment will vary according to the etiology. This article describes the author's results of a Partial Ablation of the Orbital Portion of the lacrimal gland (PAOP) under local anesthesia. Twelve adult patients, six diagnosed with HT and six with a previous dacryocystectomy, underwent surgery performed by a single surgeon in his office setting between the years 2011-2017. The average follow-up lasted 14 months, ranging from six months to three years. All patients fully recovered without any other medical or surgical intervention. Two patients experienced dry eye symptoms during the first three months after surgery but experienced relief with ocular lubricants.
\end{abstract}

Keywords: Epiphora; Watering eyes; Lacrimal gland; Lacrimal obstruction; Skin maceration; Dermatitis; Botulin toxin

\section{Introduction}

Epiphora, excessive tearing or watery eyes, is a frequent ophthalmological complaint that causes blurry vision, burning sensation, itchiness, unpleasant swelling at the inner canthus and skin maceration. The skin around the affected eye is generally erythematous and flaky, especially at the medial and lateral canthus, due to frequent rubbing $[1,2]$. It is most frequent in elderly patients and females although on occasion, it can also be found in newborns. Epiphora can occur continuously or intermittently and is a common symptom of many conditions, such as eyelid malposition (Figure 1), anterior segment inflammations of the eye, Hypersecretion of Tears (HT), drainage obstruction, rhino-sinus abnormalities, cranial nerve V system dysfunctions, and Bell's palsy syndrome, among others.

The treatment of epiphora varies according to the etiology [3-6]. In this article, the authors describe their experience with twelve patients diagnosed with epiphora, six due to HT and six due to a previous dacryocystectomy. All patients fully recovered after partial removal of the orbital Portion of the Lacrimal Gland (PAOP).

\section{Methods}

Twelve patients, eight women and four men between the ages of sixty-two and eighty-four with permanent epiphora (three of them bilateral), were treated with the PAOP technique performed by one surgeon Jorge Schwember (JS) between 2011-2017. Six of these patients had a dacryocystectomy and the other six were diagnosed with HT. Four patients were receiving treatment for hypertension, two had diabetes mellitus controlled with hypoglycemic medication, and another had hypothyroidism treated with a supplementary thyroid hormone. There were no additional significant health conditions in the cohort. Informed consent was obtained for each procedure, and the review adhered to the standards of the Declaration of Helsinki. Candidates included any person with epiphora without any other ocular or predispositional abnormalities. The Jones II test was normal in HT patients. To confirm the HT diagnosis, the patients underwent an ear, nose, and throat examination including an X-Ray Waters projection and a rhinomanometry. All patients were from the private practice of the senior author (JS) and all surgeries were performed at the office under local anesthesia and mild sedation. The removed mass of the HT patients was sent for a histopathological study. Topical antibiotics and steroid eye drops were instilled four times a day for one week. The follow-up visits were scheduled at two days, one month, three months and six months after surgery. Complications were recorded.

\section{Surgical technique}

Surgery was performed in the office setting under local anesthesia with light oral sedation using $5 \mathrm{mg}$ Valium. Topical proparacaine hydrochloride $0.5 \%$ eye drops were instilled first. A linear mark of 12 to $15 \mathrm{~mm}$ along the upper lateral lid crease was made for the incision (Figure 2). A lacrimal nerve block was performed with 0.5 cc of lidocaine $2 \%$ plus epinephrine 1:100,000. The surgical area was 

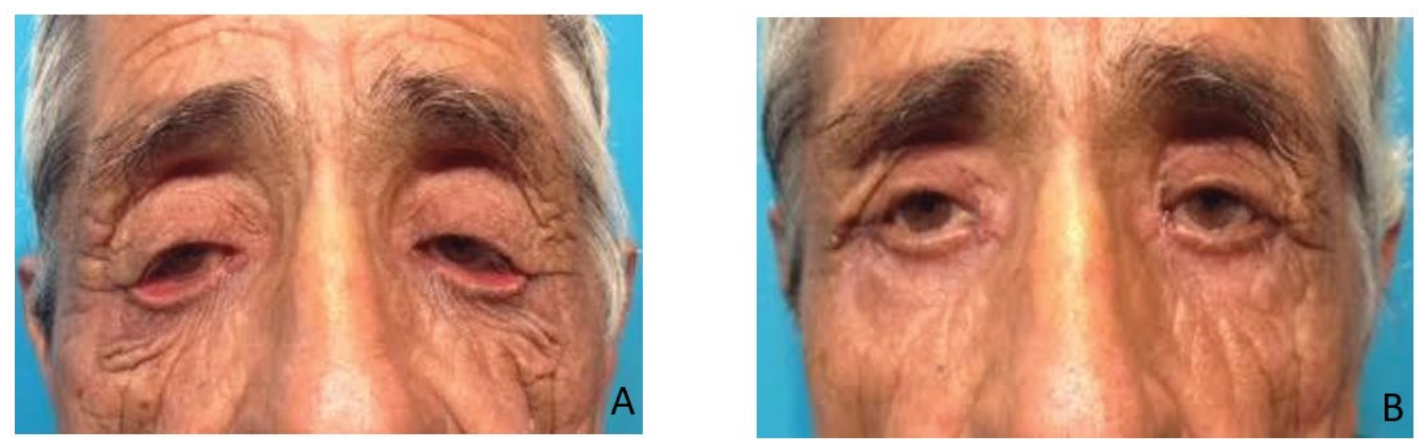

Figure 1: A-Dermatochalasis, upper eyelid ptosis, ectropion and canthal distopia of a seventy-two year old man. B-Postoperative at 6 months.

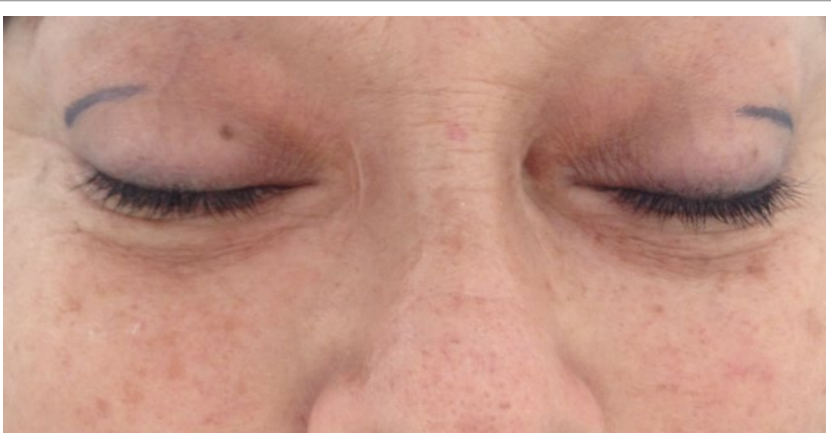

Figure 2: A bilateral case due to a previous dacryocystectomy (Notice the inner canthal surgical scars).

subcutaneously infiltrated with the same anesthetic solution. After 10 minutes, a blunt dissection was carried out to expose the orbital portion of the lacrimal gland (Figure 3). Half of the orbital portion was removed and sent to the lab for a histopathological study. Bipolar electrohemostasis was carried out. The incision was closed on two planes with catgut $5 / 0$, Steri-Strip TM tape was applied and finally, an ice pack was placed over the affected area for several hours.

\section{Results}

The removal of half of the lacrimal orbital portion eliminated the epiphora in all patients clinically diagnosed with it. To the author's knowledge to date, there are no widely accepted methods to objectively measure a decrease in lacrimal flow, opposite to a dryness condition to be assessed with a Schirmer's test. A phenol red thread test and breakup time were carried out at every follow-up visit with normal results. However, two patients complained of waking up with the dryness of the eye and required a nightly application of an ointment lubricant for three months until the symptoms subsided.

The histopathological study of the resected mass confirmed normal orbital lacrimal gland tissue in all HT patients (Figure 4).

\section{Discussion}

Botulin toxin has been advocated for the treatment of epiphora regardless of its cause, including lacrimal obstruction $[7,8]$. The authors were led to consider PAOP due to their negative experience with the use of botulin toxin to block lacrimal gland production. In their opinion, apart from the fact that it is a reiterative treatment, more than half of the patients suffered ptosis and some experienced diplopia with 2.5 units.
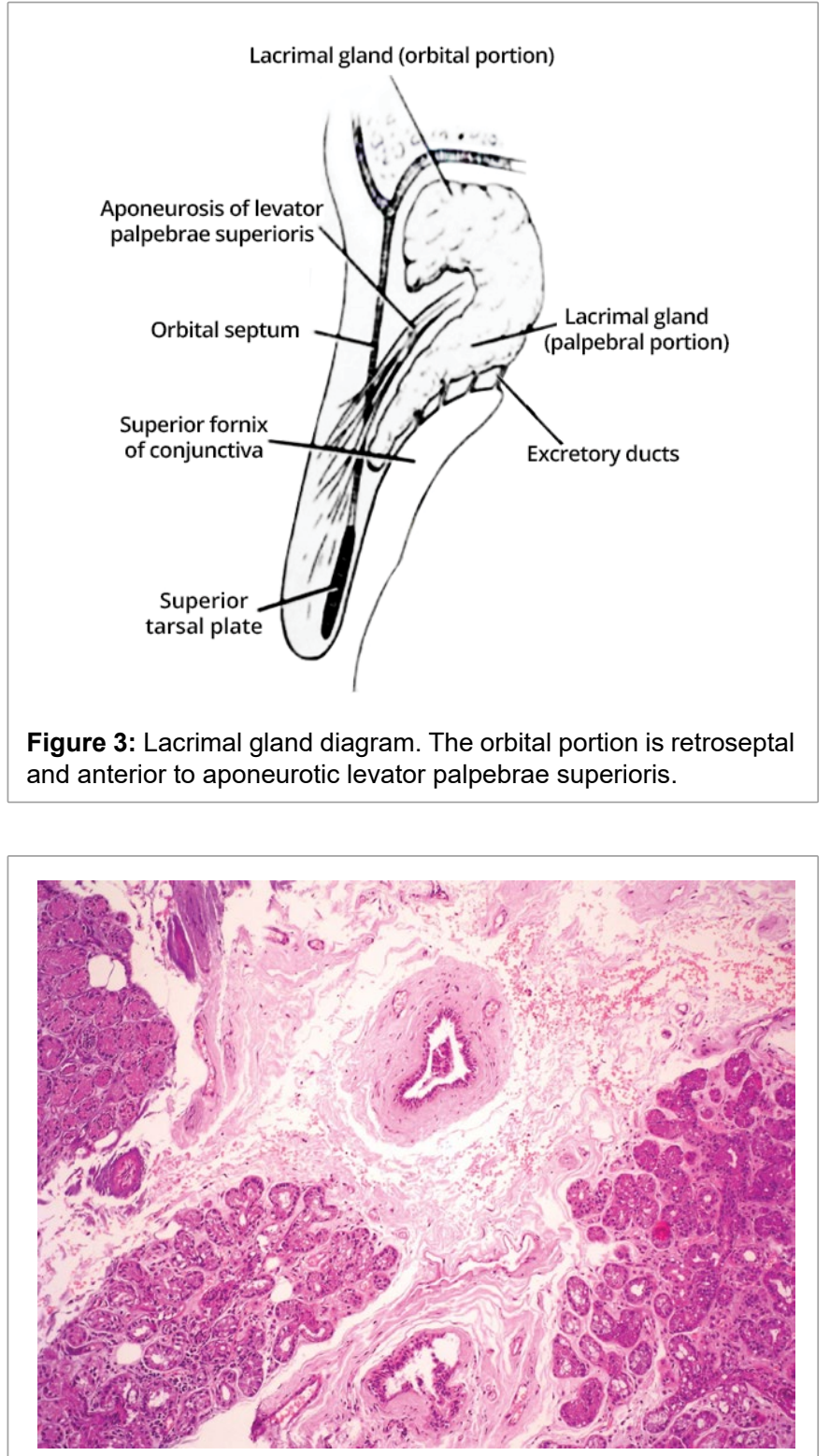

Figure 4: Histological section of $4 \mu \mathrm{m}$. Fixation in formaldehyde. Hematoxylin and eosin staining. Magnification 10x. Lacrimal glandular of acinar and ductal architecture preserved. There are no signs of atrophy or inflammation. 

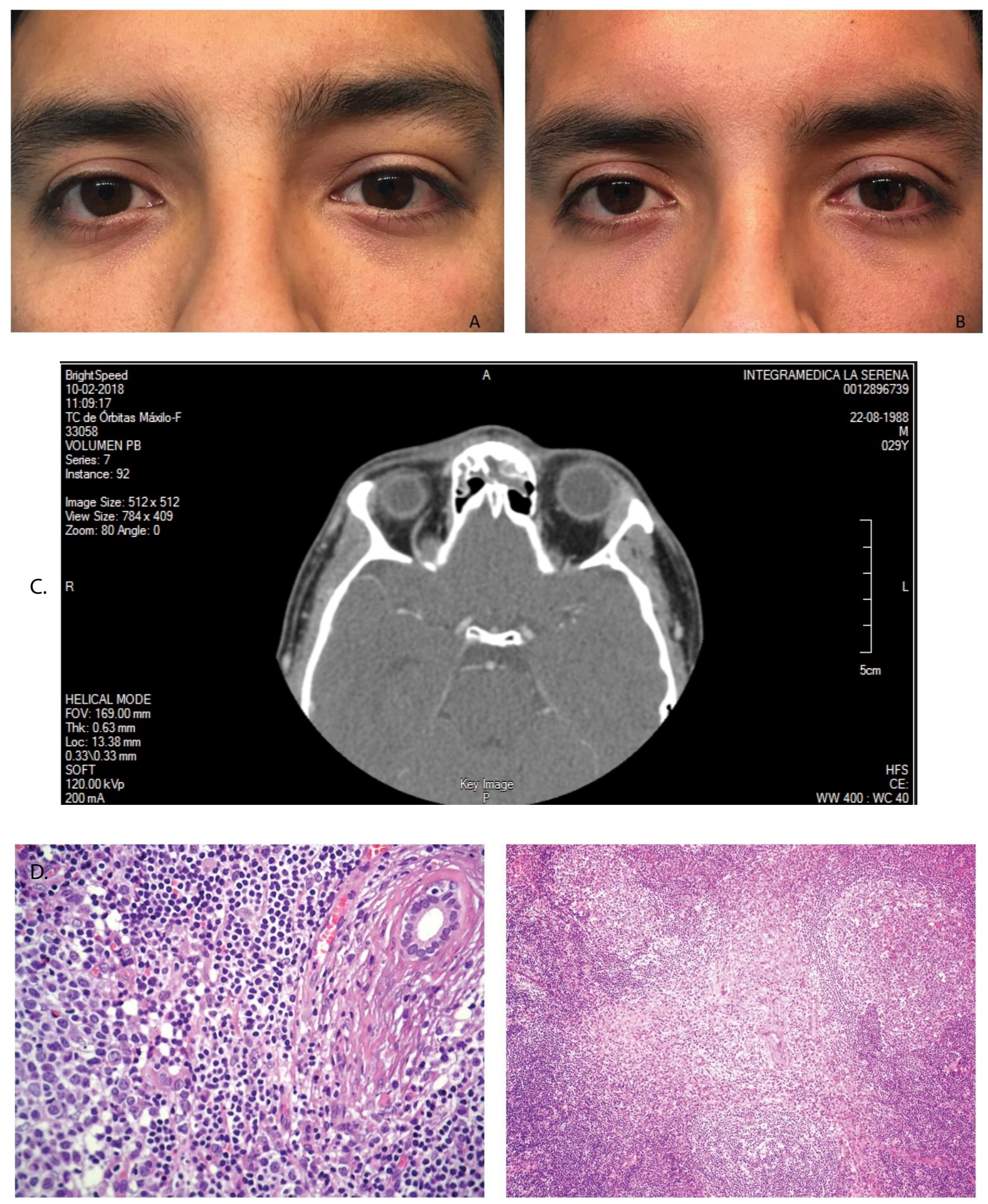

Figure 5: Male patient, 32 years old.

A-Preoperative, notice the dissimilar upper lid folds.

B-Six months after left lacrimal gland removal.

C-Orbital CT scan: mild exophthalmos due to diffuse growth of the lacrimal gland.

D-Histopathological study is compatible with Mikulicz syndrome. 

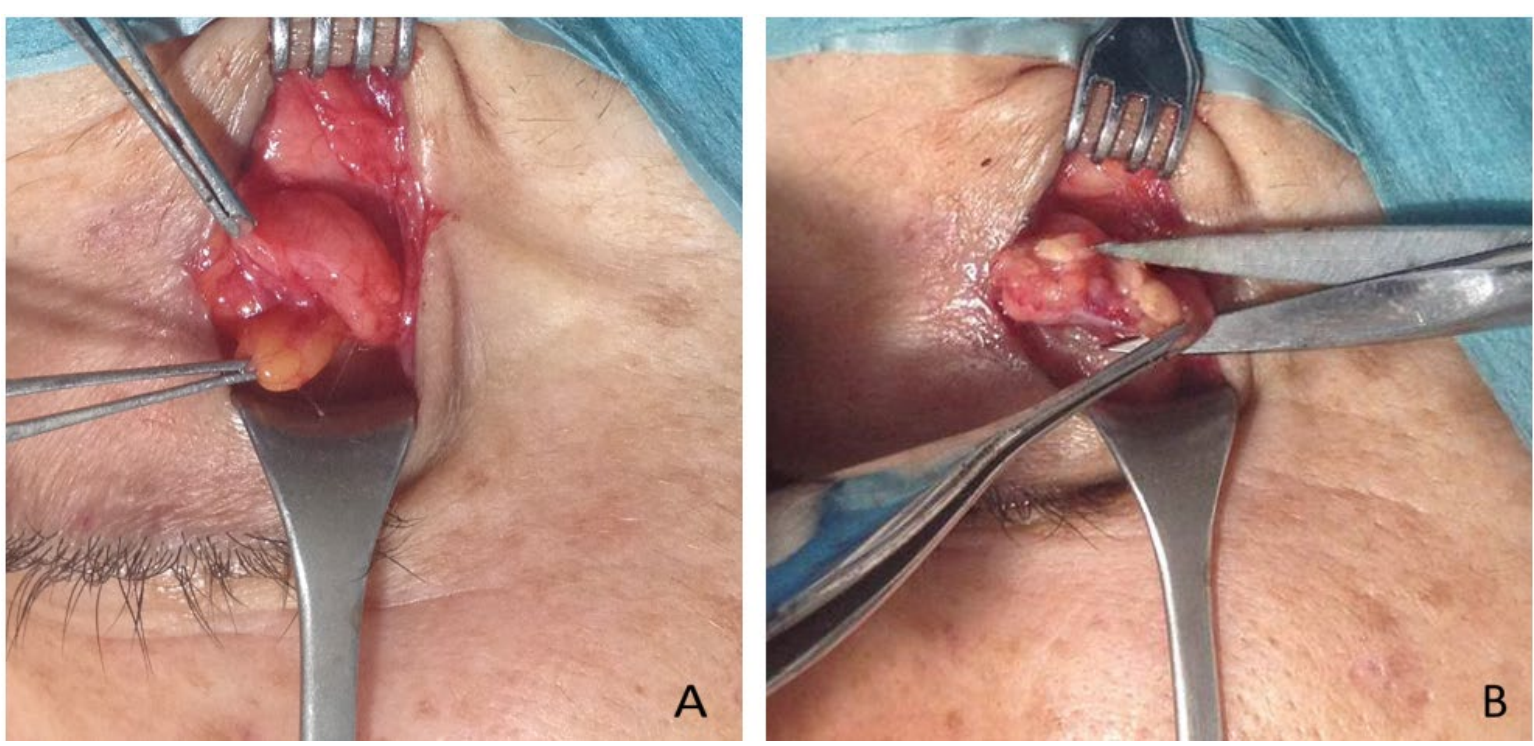

Figure 6: Surgical technique.

A-The orbital portion of the lacrimal gland is distinguishable by its location, firmness and color from the eye fat pad. B-Partial removal of the orbital portion.

Ninety-five percent of tears are produced by the lacrimal gland while the remaining five percent comes from calciform cells and secondary conjunctival lacrimal glands [9]. The deficit of tears can cause Keratoconjunctivitis Sicca, a vision-threatening condition.

The orbital portion is approximately double the size of the palpebral portion. The excretory ducts, about twelve in number, open into the superior conjunctival fornix $4-5 \mathrm{~mm}$ above the upper border of the tarsus (Figure 3).

Duke-Elder SS [10] asserts that the excision of the main lacrimal gland rarely causes serious side effects. Some authors confirm this supposition [11,12] while others reject the removal, including the excision of the orbital lobe $[13,14]$. The authors have confirmed that ablation of the lagrimal gland has no collateral results, treating four cancer patients who required the whole removal of the gland. As seen in figure 5, a patient with Mikulicz's lacrimal gland involvement suffered no type of visual impairment after the surgical ablation, such as keratitis, corneal ulcers, corneal perforations.

The authors were unable to find any mention of partial ablation of the orbital lobe as treatment for epiphora in medical literature.

The percentage of tear production that can be attributed to each of the lobes of the main gland is unclear and considering that the palpebral portion contains the excretory ducts, any intervention on this portion is inadmissible. However, if dry eye symptoms are present after the PAOP, as occurred in two patients, there are many long lasting eye lubricants that can be applied. There is also the simple option of introducing silicon punctum plugs or permanently closing the lacrimal punctum.

Patients with dacryocystectomy frequently undergo conjunctivodacryocystorhinostomy, an invasive surgery requiring general anesthesia and hospital stay [15], which could be avoided with the proposed PAOP.

There are few publications related to epiphora due to HT [16]. One post-surgical complication is ptosis, therefore great caution is required by the surgeon to avoid touching the lateral horn of the levator. This anatomical reference is crucial to identify this part of the lacrimal gland. In some patients, there is a lateral extension of the central preaponeurotic fat pad, anterior to the orbital lobe. The orbital lobe can be distinguished from the fat by its brownish color and firmness (Figure 6).

At present, the authors are inclined to consider PAOP for treatment of epiphora, especially in elderly patients with healthy conjunctiva. Neither the removal of the lacrimal glands nor botulin toxin are indicated in babies and it is the authors experience that the best method to treat babies with neonatal epiphora is to press the lacrimal sac area with a cotton swab before considering a surgical procedure to clear the lacrimal obstruction [17]. The same maneuver is feasible in adults to verify lacrimal patency and to discard a possible infection of the lacrimal ducts.

\section{Conclusion}

Removal of half of the orbital portion of the lacrimal gland is an innovative and effective procedure for epiphora due to HT or the absence of drainage. Since botulin toxin has been proposed for this and other causes of epiphora $[18,19]$, the authors are also considering the possibility of PAOP in some cases of lacrimal obstruction other than HT or in the absence of lacrimal drainage, especially in elderly patients.

\section{Declaration of Conflicting Interests}

The authors declare no potential conflicts of interest with respect to the research, authorship, and/or publication of this article.

\section{Acknowledgments}

The authors would like to acknowledge Paulina Vildosola for her quality drawings, Holly Hopkins and Caroldiana Schneider for their feedback on the manuscript.

\section{Funding}

The authors received no financial support for the research, authorship, and/or publication of this article. 


\section{Authors' Biographies}

Jorge Schwember, MD, is a graduate of the Universidad de Chile, and is a certified ophthalmologist having received his ophthalmology training at the same university. His subspecialty is oculofacial surgery, receiving his training at Hospital Defeitos da Face, Sao Paulo, Brazil. He has been working in a private practice for 40 years.

Carlos Barría, MD, MBA is a graduate of the Universidad de Chile, and is a certified pathologist of the Universidad Católica de Chile.

Luisa Madrid, MD, is a graduate of the Universidad de Chile, and is a certified ophthalmologist having received her ophthalmology training at the same university.

Luisella Yori, MD, is a graduate of the Universidad Católicadel Norte, and is currently working as a general practitioner.

Fabiola Bustamante, is a senior-year medical student of Universidad Mayor, and is currently working as a resident.

\section{References}

1. Charcot JM (1877) Lectures on the diseases of the nervous system. New Sydenham Society 63: 126.

2. Yen MT, Yen KG, Anderson RL (2003) Perivascular Dermatitis of the Eyelid Secondary to Chronic Epiphora. Invest Ophthalmol Vis Sci 44: 2423.

3. Mainville N, Jordan DR (2011) Etiology of tearing: a retrospective analysis of referrals to a tertiary care oculoplastic practice. Ophthalmic Plast Reconstr Surg 27: 155-157.

4. Sibley D, Norris JH, Malhotra R (2013) Management and outcomes of patients with epiphora referred to a specialist ophthalmic plastic unit. Clin Exp Ophthalmol 41: 231-238.

5. Shams PN, Chen PG, Wormald PJ, Sloan B, Wilcsek G, et al. (2014) Management of functional epiphora in patients with an anatomically patent dacryocystorhinostomy. JAMA Ophthalmol 132: 1127-1132.

6. Moscato EE, Dolmetsch AM, Silkiss RZ, Seiff SR (2012) Silicone intubation for the treatment of epiphora in adults with presumed functional nasolacrimal duct obstruction. Ophthal Plast Reconstr Surg 28: 35-39.
7. Wojno TH (2011) Results of lacrimal gland botulinum toxin injection for epiphora in lacrimal obstruction and gustatory tearing. Ophthalmic Plast Reconstr Surg 27: 119-121.

8. Tu AH, Chang EL (2005) Botulinum toxin for palliative treatment of epiphora in a patient with canalicular obstruction. Ophthalmology 112: 1469-1471.

9. Garg A, Sheppard JD, Donnenfeld ED, Meyer D, Mehta CK (2006) Clinical Diagnosis and Management of Dry Eye and Ocular Surface Disorders (Xero-Dacryology). Jaypee Brothers Medical Publishers.

10. Duke-Elder SS (1965) System of Ophthalmology: Diseases of the outer eye. $2^{\text {nd }}$ Edition, Mosby, The University of Michigan 8: 128.

11. Fox SA (1973) Palpebral dacryoadenectomy. Am J Ophthalmol 76: 314-316.

12. Bhattacharya D, Ning $Y$, Zhao F, Stevenson W, Chen R, et al. (2015) Tear Production After Bilateral Main Lacrimal Gland Resection in Rabbits. Invest Ophthalmol Vis Sci 56: 7774-7783.

13. Scherz W, Dohlman CH (1975) Is the lacrimal gland dispensable? Keratoconjunctivitis sicca after lacrimal gland removal. Arch Ophthalmol 93: 281-283.

14. Taiara C, Smith B (1973) Palpebral dacryoadenectomy. Am J Ophthalmol 75: 461-465.

15. Schwember J, Schwember G, Madrid L (1984) Conjuntivodacriocistorrinostomía. Arch Chil Oftalmol 41: 87-91.

16. Royer J (1968) Diagnosis and treatment of epiphora due to hypersecretion (the tear ducts being physiologically permeable). Ann Ocul (Paris) 201: 941-945.

17. Schwember J, Madrid L (2018) Congenital Lacrimal Obstruction. Int J Ped Neo Heal 2: 56.

18. Whittaker KW, Matthews BN, Fitt AW, Sandramouli S (2003) The use of botulinum toxin $A$ in the treatment of functional epiphora. Orbit 22: 193-198.

19. Kaynak P, Karabulut GO, Ozturker C, Fazil K, Arat YO, et al. (2016) Comparison of botulinum toxin-A injection in lacrimal gland and conjunctivodacryocystorhinostomy for treatment of epiphora due to proximal lacrimal system obstruction. Eye (Lond) 30: 1056-1062. 